medication were: performing DXA scan $(\mathrm{aOR}=9.9,95 \% \mathrm{Cl}[7.7,12.6])$, fragility fracture $(\mathrm{aOR}=2.8,95 \% \mathrm{Cl}[1.8,4.5])$, and osteoporosis or osteopenia diagnosis $(\mathrm{aOR}=2.5,95 \% \mathrm{Cl}[2.0,3.1])$

Conclusion: We describe temporal trends in bisphosphonate discontinuations and factors associated with discontinuation of alendronate and restart of osteoporosis therapy. From 2010 to 2015, approximately one-third of women with longterm bisphosphonate treatment discontinued treatment for $\geq 12$ months. We observed an increasing trend in discontinuation from 2010 to 2012, which remained steady through 2015 . Factors associated with discontinuation of alendronate were associated with worsening of overall health status, while factors traditionally associated with worsening bone health were associated with restart of osteoporosis medication.

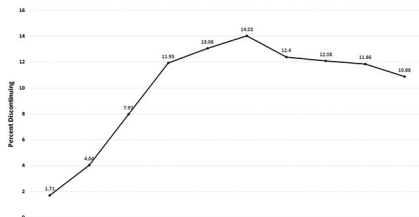

Figure 1. Temporal trends of Bisphosphonate Discontinuation in U.S. Medicare women beneficiaries by calendar year

Disclosure of Interests: Giovanni Adami: None declared, Ayesha Jaleel: None declared, Jeffrey Curtis: None declared, Rui Chen: None declared, Huifeng Yun Grant/research support from: BMS, Pfizer, Shanette Daigle: None declared, Tarun Arora Grant/research support from: Amgen, Maria Danila Grant/research support from: Pfizer, Inc., Consultant for: Sanofi Genzyme \& Regeneron, Nicole Wright Grant/research support from: Amgen, Consultant for: NortonRose Fulbright/Pfizer, Suzanne Cadarette: None declared, Amy Mudano: None declared, Jeff Foster: None declared, Kenneth Saag Grant/research support from: Amgen, Ironwood/AstraZeneca, Horizon, SOBI, Takeda, Consultant for: Abbvie, Amgen, Ironwood/AstraZeneca, Bayer, Gilead, Horizon, Kowa, Radius, Roche/Genentech, SOBI, Takeda, Teijin

DOI: 10.1136/annrheumdis-2019-eular.1626

\section{OP0083 PREVALENCE OF VERTEBRAL FRACTURES IN POSMENOPAUSAL WOMEN WITH RHEUMATOID ARTHRITIS}

Carmen Gómez Vaquero ${ }^{1}$, Dacia Cerda ${ }^{2}$, Cristina Hidalgo ${ }^{3}$, Ja Martínez López ${ }^{4}$, Luis Marcelino Arboleya Rodríguez ${ }^{5}$, Javier Aguilar del Rey ${ }^{6}$, Silvia Martinez Pardo ${ }^{7}$, Inmaculada Ros ${ }^{8}$,Xavier Surís ${ }^{9}$, Dolors Grados ${ }^{10}$, Chesús Beltrán ${ }^{11}$, Evelyn Suero-Rosario ${ }^{12}$,Inmaculada Gómez Gracia ${ }^{13}$ Asunción Salmoral $^{13}$, Irene Martín-Esteve ${ }^{12}$, Helena Florez ${ }^{14}$, Antonio Naranjo ${ }^{15}$, Santos Castañeda ${ }^{16}$, Soledad Ojeda ${ }^{15}, \mathrm{~S}$ García Carazo ${ }^{17}$, Alberto GarcíaVadillo $^{16}$, Laura López Vives ${ }^{18}$, À Martínez-Ferrer ${ }^{19}$, Helena Borrell ${ }^{18}$, Pilar Aguado ${ }^{17}$, Raul Castellanos-Moreira ${ }^{14}$, Núria Guañabens ${ }^{14}$, OsteoResSer Working Group of the Spanish Society of Rheumatology. ${ }^{1} \mathrm{H} . \mathrm{de}$ Bellvitge, L'Hospitalet, Spain; ${ }^{2}$ H.Sant Joan Despí Moisès Broggi, Esplugues, Spain; ${ }^{3}$ H.de Salamanca, Salamanca, Spain; ${ }^{4}$ H.Fundación Jiménez Díaz, Madrid, Spain; ${ }^{5} \mathrm{H}$. Central de Asturias, Oviedo, Spain; ${ }^{6} \mathrm{H}$. Virgen de la Victoria, Málaga, Spain; ${ }^{7} \mathrm{H}$. Mutua Terrassa, Terrassa, Spain; ${ }^{8} \mathrm{H}$. Son Llàtzer, Palma Mallorca, Spain; ${ }^{9} \mathrm{H}$. General de Granollers, Granollers, Spain; ${ }^{10} \mathrm{H}$.d'lgualada, Igualada, Spain; ${ }^{11} \mathrm{H}$. Miguel Servet, Zaragoza, Spain; ${ }^{12}$ H.General Mateu Orfila, Maó, Spain; ${ }^{13}$ H.Reina Sofía, Córdoba, Spain; ${ }^{14}$ H.Clínic de Barcelona, Barcelona, Spain; ${ }^{15}$ H.de Gran Canaria Dr. Negrín, Las Palmas Gran Canaria, Spain; ${ }^{16} \mathrm{H}$.de La Princesa, Madrid, Spain; ${ }^{17}$ H.La Paz, Madrid, Spain; ${ }^{18} \mathrm{H}$.de Sant Rafael, Barcelona, Spain; ${ }^{19} \mathrm{H}$. Doctor Peset, Valencia, Spain

Background: Rheumatoid arthritis (RA) is a risk factor for the development of fragility fractures, but there is little quality data on its prevalence. Conversely, osteoporosis is one of the most frequent comorbidities of RA.

Objectives: To determine the prevalence of vertebral fractures in postmenopausal women with RA and to analyse their characteristics and associated risk factors.

Methods: We included 346 postmenopausal women diagnosed with RA according to the ACR/EULAR 2010 criteria in 19 Spanish Rheumatology Departments, randomly selected from the registry of $R A$ patients in each center, recruited during 2018. Lateral radiographs of the dorsal and lumbar spine were obtained from all patients, to evaluate morphometric vertebral fractures. Expert rheumatologists identified vertebral fractures and classified them into mild (grade 1: reduction of height of $20-25 \%$ ), moderate (grade 2 : reduction of $26-40 \%$ ) and severe (grade 3 : reduction $>40 \%$ ), according to the Genant grading scale. The spinal deformity index (SDI) was calculated by assigning numbers 1,2 and 3 to each fractured vertebra and adding the total score of each patient. The study variables were: a) age, body mass index (BMI), b) factors related to RA: time of evolution, FR ACPA, and c) fracture risk factors: prior fragility fracture, parental hip fracture, glucocorticoids, smoking, alcohol intake $\geq 3$ units daily, secondary osteoporosis and time since menopause.

Results: The mean age was 66.8 (SD: 10.1) years and the median evolution of the disease, 8.00 [RIQ: 3.00-15.5] years. $77.2 \%$ (n: 267$)$ and $75.7 \%(n: 252)$ had $\mathrm{FR}$ and ACPA +, respectively. The mean duration of the postmenopausal period was 15.0 (SD: 9.6 ) years. $23.4 \%$ ( $\mathrm{n:} 79$ ) of patients had at least one vertebral fracture; $10.7 \%$ ( $n: 36$ ) had a single fracture and $12.7 \%(n: 43)$, multiple fractures. The most fractured vertebrae were D12, L1 and L2 (fractured in $>5 \%$ of patients). The median SDI was 3 [RIQ: 2-5]. The vertebrae with the highest mean IDE were D8 D10, D11 and L1 (all mean IDE $\geq 2$ ). An association was found between the presence of vertebral fractures and age, height, postmenopausal period, time of dis ease progression, glucocorticoid treatment and parental hip. No linear association was found between SDI and age, time of evolution of the disease, BMI and time since menopause.

Conclusion: One out of every 4 postmenopausal women with RA has at least one vertebral fracture. Vertebrae of the dorso-lumbar hinge are the most frequently involved and the magnitude of the spinal deformity is relevant. Vertebra fractures are related to the time of evolution of RA and to the risk factors for fracture.

Disclosure of Interests: Carmen Gómez Vaquero: None declared, Dacia Cerda: None declared, Cristina Hidalgo: None declared, JA Martínez López: None declared, Luis Marcelino Arboleya Rodríguez: None declared, Javier Aguilar del Rey: None declared, Silvia Martinez Pardo: None declared, Inmaculada Ros: None declared, Xavier Surís Speakers bureau: Lilly, Pfizer, MSD, Dolors Grados: None declared, Chesús Beltrán: None declared, Evelyn Suero-Rosario: None declared, Inmaculada Gómez Gracia: None declared, Asunción Salmoral: None declared, Irene Martín-Esteve: None declared, Helena Florez: None declared, Antonio Naranjo: None declared, Santos Castañeda Consultant for: Amgen, BMS, Pfizer, Lilly, MSD, Roche, Sanofi, UCB, Soledad Ojeda Grant/ research support from: AMGEN, Speakers bureau: AMGEN, S García Carazo: None declared, Alberto García-Vadillo: None declared, Laura López Vives: None declared, À Martínez-Ferrer: None declared, Helena Borrell: None declared, Pilar Aguado: None declared, Raul Castellanos-Moreira Speakers bureau: MSD, Lilly, Núria Guañabens Consultant for: Advisory Boards from Amgen, Alexion and UCB, Speakers bureau: Fees and lectures from Eli Lilly DOI: 10.1136/annrheumdis-2019-eular.6758

\section{OP0084}

FRAGILITY HIP FRACTURES - DOES DESTINATION AFTER HOSPITAL DISCHARGE HAVE AN IMPACT ON PATIENT'S OUTCOME?

Miguel Guerra ${ }^{1}$, Sara Ganhão², Francisca Aguiar², Raquel Ferreira²,

Teresa Martins-Rocha ${ }^{2}$, Ana Filipa Águeda ${ }^{3}$, Georgina Terroso ${ }^{2}$, Carlos Vaz ${ }^{2,4}$, Lúcia Costa ${ }^{2}$. Centro Hospitalar de Vila Nova de Gaia/Espinho, Department of Rheumatology, Vila Nova de Gaia, Portugal; ${ }^{2}$ Centro Hospitalar e Universitário de São João, Department of Rheumatology, Oporto, Portugal; ${ }^{3}$ Centro Hospitalar do Baixo Vouga, Department of Rheumatology, Aveiro, Portugal; ${ }^{4}$ Oporto University, Faculty of Medicine, Oporto, Portugal

Background: In Osteoporosis, hip fractures account for significant disease burden, with increased morbi-mortality. Because of this, patients are referred to rehabilitation and specific health care units, in order to regain autonomy and health However, there is few evidence about patients' outcome, considering destination after inpatient discharge.

Objectives: To evaluate if destination after hospital discharge for a osteoporotic hip fracture has impact in the outcome (mortality and new fracture).

Methods: Patients referred to a Fracture Liaison Service from March 2015 until March 2017 with a fragility hip fracture were considered for this study. Clinical/ demographic variables were retrospectively collected until January 2018 , including destination at discharge (home, nursing home $(\mathrm{NH})$, inpatient rehabilitation unit $(\mathrm{RU})$ ) and outcome (death, new fracture, lost to follow-up). Kaplan Meyer curves with log-rank test were used for statistical analysis (SPSS statistics 23); $\mathrm{p}<=0.05$ was considered statistically significant.

Results: From a total of 522 patients, 437 patients were discharged with a known destination: $58.1 \%$ to home $(n=254), 27.7 \%$ to a $R U$ and the remaining to a $\mathrm{NH}$ Table 1 summarizes clinical and demographic characteristics of the sample. Seventy-four patients died (median time $=264$ days, range 22-1049) and 43 suffered a new fracture (median time 301, 15-946); 129 patients maintained follow-up. Mortality rates within each group of discharged patients were: $15.4 \%$ in the group des tined home, $22.6 \%$ in the group forwarded to a NH and $17.4 \%$ in those referred to a RU. No statistically significant difference was found in cumulative survivals between groups (figure 1A). The event refracture was observed in $10.2 \%$ of those discharged home, $6.5 \%$ in the group forwarded to a $\mathrm{NH}$ and $10.7 \%$ of those referred to a RU. Again, no statistically significant difference was observed (figure 1B). 